\title{
NANODISCS: A NEW EPOCH IN THE STUDY OF MEMBRANE PROTEINS AND AS AN EMERGING DRUG DELIVERY SYSTEM
}

\section{ARYA G. K., ANJALY A. KUMAR, ARCHANA J. NAIR, JENI RAJU, SREEJA C. NAIR*}

Department of Pharmaceutics, Amrita School of Pharmacy, Amrita Vishwa Vidyapeetham, AIMS Health Science Campus, Kochi, India. Email: sreejacnair@aims.amrita.edu

Received: 10 Jul 2018, Revised and Accepted: 19 Nov 2018

\begin{abstract}
Nano discs recently evolved as a novel tool for studying the membrane associated proteins and serve as an effective drug delivery system. Nano discs constitute disc shaped nano particles and can be defined as a membrane system which is synthetic in nature and aids in the study of membrane proteins. It is mainly made of phospholipid bilayer and the water repelling edge is isolated by amphipathic proteins called Membrane Scaffolding Proteins [MSP]. Micelles present in the nano disc mimics the property of the biological membrane proteins. It is a powerful technology that competently delivers the drug components in to the right cells in the right tissues. Membrane scaffold proteins are primarily expressed, purified and characterized and self-assembled to form Nano discs by the process of dialysis using biobeads. Nano discs are proven to be effective in the study of membrane proteins because they can fluidize and counterbalance and also help in reclusion, refinement, biophysical and biochemical studies of them. It also presents a more genuine environment than liposomes, bicelles, amphipols and detergent micelles. Major technological advantages of nano discs include the higher stability and carrier capacity and also the increased feasibility of incorporating both hydrophilic and hydrophobic substances of drug carrier. Thus nano discs serves as an excellent system in its ability to precisely control its composition and provide a nano scale membrane surface for investigating molecular recognition events. This article reviews the emphasis of nanodiscs in studying membrane proteins as well as its effectivity in transforming into a major drug delivery system. An overview of published literatures between 1996 and 2017 was conducted to write the review.
\end{abstract}

Keywords: Membrane Scaffolding Proteins, Phospholipid bilayer, Hydrophobic beads, High densitylipoproteins

(c) 2019 The Authors. Published by Innovare Academic Sciences Pvt Ltd. This is an open access article under the CC BY license (http://creativecommons.org/licenses/by/4.0/] DOI: http://dx.doi.org/10.22159/ijap.2019v11i1.28398

\section{INTRODUCTION}

\section{What is nano drug delivery?}

The technique by which drug delivery is achieved has a vital role in its performance. 'Nanoparticles are solid colloidal dispersions having their size in nanometer range [10-1000 nm] [1]. They have the capacity to transform poorly soluble, poorly absorbable, liable biologically active substances into promising deliverable drugs. Nanoparticles have tremendous potential in effective drug delivery. The drug to be delivered is dissolved, encapsulated, entrapped or incorporated into a nanoparticle matrix system. The most common method is by loading the therapeutic agents within the nano particles [2]. Due to the very small size and miniscule diameter, it can easily penetrate the blood capillaries and reach the target site and effectively deliver the drug in the required therapeutic concentrations [3]. Thus by doing in this way, it reduces drug toxicity as well as side effects and enhances drugefficacy. Nanotechnology has gained publicity these days to overcome the problems of gene and drug delivery [4]. The widespread improvements in technological innovations have begun to change the fundamentals of diagnosis, treatment and prevention of diseases. Such technological innovations are referred to as nano medicines [5] and they have the potential to convert upcoming molecular discoveries from proteomics and genomics into huge beneficiary aspects for the patient [6].

\section{Why nano drug delivery?}

The rapid enhancement and progress in nanotechnology during the last years has found out that drug delivery methodologies involving nanoparticles will serve effectively as well as efficiently [7] Even, nano gold particles has found its application in the field of bio pharmaceutics [8]. Nanoparticles have the potential to deliver the therapeutic agents accurately as well as carefully into the target site, whether it is an organ, tissue or even a specific cell and also result in the precise release of the drug at the target site. Because of the colloidal nature and a very small diameter(less than $1000 \mathrm{~nm}$ ), they can penetrate through the capillaries into the internal apparatus of even a single cell. The traditional drug delivery methods such as oral route and injection etc. may also find less applicable due to the following reasons, the most common one being the destruction of the drugs at common doses by the stomach as well as the intestinal juices. Thus it will result in poor or hampered absorption of the drugs into the body and will be non-productive or useless. The new evolution of nano drug delivery can compensate this in a promising way [9]. Nanoparticles are proven to have some additional advantages when compared with micro particles due to increased range of intracellular uptake, relative mobility and availability to large areas of biological targets. The small size, increased rate of solubility customised surface and multi functionality of nanoparticles will open a wider access to create newer applications of biomedicine. Thus the therapeutic as well as pharmacological actions of the drug being administered are enhanced. Moreover the novel properties of nanoparticles provide the possibility to interact with complex cellular functions [10]. Nanoparticles have the ability to mimic biological properties [e. g.: tissue engineering, infection] [11]. The development of huge nano scale interventions will change the scientific landscape in terms of diagnosis, prevention and treatment of illness. Interactions of nano particles with biological environment, therapeutic agent stability, cell signalling mechanisms, cell surface receptor targeting etc. are essential to attain effective drug delivery. Anticancer drugs like paclitaxel, dexamethasone and doxorubicin etc. have been formulated successfully using nanoparticles [12]. One of the most difficult malignancies to detect and treat is the brain cancer. The main problem residing with this is the difficulty in in getting imaging and the passing of therapeutic agents via the blood brain barrier and into the brain. Anticancer drugs like lopramide and doxorubicin bound to nano materials have proven to cross the blood brain barrier and released at therapeutic concentrations in the brain [13]. Nanoparticles used in drug delivery systems, for instance ophthalmic drug delivery are usually less than 100 nano meter and is composed of biodegradable materials like lipids, natural or synthetic polymers etc [14]. Cells take up nanoparticles more effectively than micro molecules and serve as the effective transporter and delivery system. Also, nanoparticles being loaded with antiviral therapeutic agents against human immuno deficiency Virus are found as an emerging as well as promising drug delivery system in the treatment of acquired immuno deficiency syndrome (AIDS) [15]. The various nano 
particles used in drug delivery include polymeric biodegradable nano particles, metallic nano particles, ceramic nano particles etc. The complete information regarding the nanoparticles used in drug delivery has been explained in Sandeep S et al. [16]. The experimentation in various micro as well as nano particles for efficient drug delivery has been checked from time immemorial, for instance magnetic microsphere experimentation for delivering drug into the colon region $[17,18]$. Nanodiscs serve as an efficient membrane system involved in nano drug delivery. The use of nanodiscs in nano drug delivery is only an evolving or emerging system. Apart from the try-outs being conducted for effectively utilising nanodiscs in nano drug delivery, nanodiscs serve the prominent role in the study of membrane proteins [19].

\section{Nanodiscs: the new revolution in membrane protein study}

Nanodiscs can be defined as disc shaped (discoidal) particles having a flattened or placoid bilayer composed of phospholipids and the bilayer is being enveloped by proteins (e. g.: apo lipoprotein A1)[20]. The bilayer is arranged in such a way that the hydrophobic end is directed inwards towards the opposite side of the film and the hydrophilic edge is directed outwards. Nanodiscs were first found out by Sligar and co-workers [21]. Nanodiscs constitute disc shaped nano particles and can also be defined as a membrane system which is synthetic in nature and aids in the study of membrane proteins [22]. It is mainly made of phospho lipid bilayer and the water repelling edge is isolated by amphipathic proteins called membrane scaffolding proteins [MSP]. They are cropped versions of apolipoprotein which cover around a strip of lipid bilayer and form a disc shaped particle or in other words nanodisc. They are arranged in a double belt model. In structure, they are identical to high density lipoproteins [23]. It is these membrane scaffolding proteins or in other words msps that determine the elongated structure of the nanodisc and it has also been found out that as temperature increases, the particle structure become more rounded or disc shaped [24]. MSPs are also involved in determining the thickness of the hydrophobic layer within the lipid bilayer. There is a chance of some disparity between the protein and phospholipid layer. This mismatch can also be challenged and overcome with the help of adjusting the scaffolding proteins. Nanodiscs are proven to be effective in the study of membrane proteins because they can fluidize and counterbalance and also help in reclusion, refinement, biophysical and biochemical studies of them. It also presents a more genuine environment than liposomes, bicelles, amphipols and detergent micelles [25]. The primary focus of nanodiscs lies in the study of membrane proteins and this can be achieved by dissolving them in solution. Peptide amphiphiles are primarily known to make nanodiscs. It is particularly composed of a peptide sequence, which is hydrophilic in nature and has a lipid chain attached to it (lipopeptide). However due to the relative unstability posed by these lipopeptides can be overcome by self-assembled amphiphilic peptides [26]. Major technological advantages of nanodiscs include the higher stability and carrier capacity and also the increased feasibility of incorporating both hydrophilic and hydrophobic substances of drug carrier [27]. A number of membrane proteins have been imbibed into nanodiscs. It include metabotropic glutamate receptor [28], parathyroid hormone 1 receptor [29], bacterial chemoreceptors [30], cholera toxin [31] etc. Nanodiscs are found in nature as HDL [32]. These lipo protein particles flow through blood and act as a vehicle for carrying cholesterol to liver for downgrading. Primarily they are disc shaped in original form and on interpolation with cholestreryl esters in the phospholipid bilayer, they assume a sphere like form [33]. The size of a nanodisc is dependent on the length of modified apo A 1 . Nanodiscs are even prepared from zebra fish apo A1 and are called as nanoscale apolipoprotein bound bilayers [22]. From human serum apolipoprotein has been directy derived and is used in the preparation of reoriented discs of lipids [34, 35].

\section{The link from lipoproteins to nanodiscs and to membrane protein} studies

A lipoprotein can be defined as a biochemical assembly of lipids and proteins and aids in the transportation of cholesterol, fatty acids and lipids in the blood. The different types of lipoproteins include LDL, HDL, very low density lipoproteins (VLDL), chylomicron among these lipoproteins, the HDL is also known as good cholestrol because of its tremendous potential in transporting cholesterol from the walls of arteries to the liver where the cholesterol is being subjected to the process of degradation [36]. The reverse cholestrol transport pathway has something important to do with the HDL particles. The reverse cholesterol transport pathway involves many steps which ultimately results in the movement of cholesterol from the peripheral cells to the liver via the plasma compartment. Conversion of cholesterol from these peripheral sites to HDL can be done with the help of adenosine triphosphate binding casette Proteins [37]. The HDL is being composed of a protein part and phospholipid part. So, here the protein component of the HDL that is apolipoproteinA1 act as an acceptor of the cholesterol particle while the phospholipid portion act as the sink. The enzyme lecithin acetyl transferase (LCAT) is involved in the conversion of cholesterol to cholesterol ester. In exchange for triglycerides, these cholestryl esters can be transferred to LDL, VLDL and other such lipoproteins. This step is being achieved with the help of a protein termed as cholesteryl ester transfer protein (CETP)[38)]. By the conversion of cholesterol into bile acids, these lipoproteins can be utilised. Another method for the take up of these lipoproteins is by secreting the non-esterified cholesterol into bile. So, the overall process of making, conversion and degradation of HDL particles is being up regulated by the reverse cholesterol transport pathway. The cholesterol moiety can then be converted to cholesteryl ester and then further to lipoproteins. Natural HDL is composed of diverse particles (heterogeneous in nature). This heterogeneity in particle nature will impede the physical as well as structural study of apolipoprotein A1 [39]. Nanodiscs can be formulated by the reconstruction of these native HDL particles. This reconstitution process can be carried out with the help of purified Apo A1 and using different lipids having or even without having cholesterol. Thus the particles turned out to a consistant (homogenous) nature [40]. Nanodiscs are the manoeuvred or skilfully arranged forms of these reorganised HDL particle mimics and under optimum conditions they can assemble themselves into disc shaped particles of uniform size and configuration [41].

\section{Nanodiscs in membrane protein studies}

Membrane Proteins have posed a greater challenge in different functional as well as biochemical studies. The major challenge lies in the difficulty to study membrane proteins from a mechanistic view point. This is because most of the chemical as well as biophysical methods which are relevant and appropriate to soluble enzymes may fail while coming in contact with the insoluble masses [42]. If the membrane protein is found in a solubilized condition, then it makes the processes like purification, assay, different biophysical and biochemical techniques, structural manipulations, spectroscopical procedures etc. simpler and also helps in sustaining the goal protein in a very stablecondition [43]. Over the past years, detergents were the main agents used in solublisation of membrane proteins and thus ultimately resulted in the formation of micelles containing detergent, membrane proteins and lipids. But the use of detergents has raised a major threat to the constancy of these membrane proteins [44]. Also the micellar stage of detergents can restrict the assay procedures and also exhibit unwanted optical properties such as in absorbance, scattering of light etc... There is also procedural difficulties with the usage of detergents and may result in denaturation as well as inactivation of the proteins (membrane proteins co concentrating with the target). Basically we can say that the traditional use of detergents in membrane protein studies posed some major challenges [45]. Mainly it interferes with the stability of the membrane protein of interest. As said above, it can not only interfere but also imped the different assay procedures. Particular phospholipids are also required to regulate the function of these membrane proteins. The limitations of these detergents resulted in the usage of liposomes for the purpose to incorporate the membrane proteins. But the liposomes also had their own limitations. The iposomes presented a large surface area, sometimes unstable and also hard to prepare with an exactly controlled stoichiometry and size.

The limitation with liposomes paved the way for the arousal of a new system termed nanodiscs [46]. In this system, the target 
membrane protein is transitorily made soluble in a detergent. The process is carried out in the presence of phospholipids and a helical protein belt, MSP which is amphipathic in nature and the belt surrounding the phospholipid bilayer. Then polystyrene beads which are hydrophobic in nature is added to the above system. This results in the elimination of detergents in such a way that the detergents get adsorbed on the surface of the biobeads. Thus the membrane protein is being placed in a native condition and the whole entity is made soluble with the help of the surrounding MSP belt. The major advantage of nanodisc technology is that it can be synthesised in different size and stoichiometry depending on the size of MSP belt used [47]. The nanodisc technology can also be made applicable to different classes of membrane Proteins. The major member among them is the MSP. What is being basically done is that monomerisation of the membrane proteins, and then we will conduct the solubilisation process. Finally, we will do the incorporation process. The protein is being incorporated into membrane environment [48]. By engineering different classes of Scaffold Proteins, different ranges of nanodiscs such as smaller, larger and medium sized nanodiscs can be constructed [49]. This can be achieved by the exact measuring of the give and take of the proteins and lipids within the nanodiscs, by the structural analysis of the consistency and uniformity of the lipoprotein complexes within them and also by explaining the kinetics of the lipo protein assembly by the use of experimental as well as theoretical procedures. The major as well as the most striking advantage of using nanodiscs is that it can be made in different size and definite stoichiometry using different MSP $s[50]$. The one dimensional view of a nanodisc has been shown in fig. 1 [8].

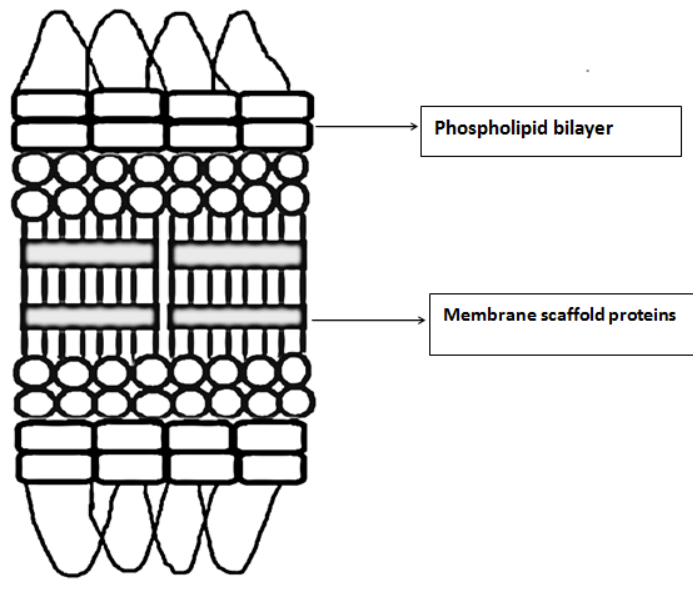

Fig. 1: One dimensional view of a nanodisc

\begin{abstract}
Advantages of nanodiscs over other systems
Nanodiscs have many advantages when compared to other sysrems. The major ones being the provision of a native environment, stability, helps in the solublisation of membrane proteins etc. Nanodisc system provide contact to both surfaceof membrane and also helps in the oligomerisation of membrane proteins. The major advantages are as shown in table 1 [24-27
\end{abstract}

Table 1: Advantages of nanodiscs over other system

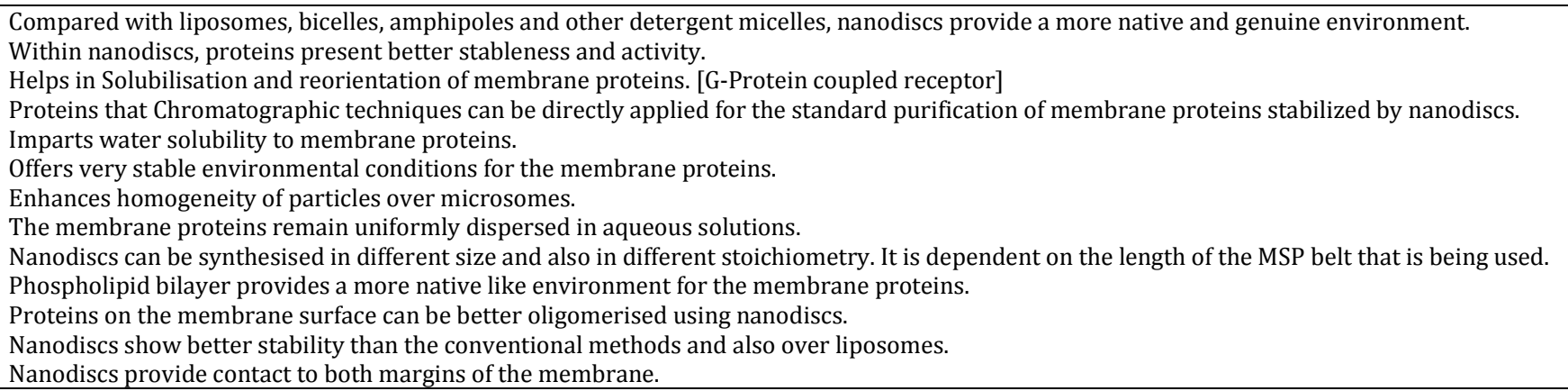

\section{Materials required for nanodisc synthesis}

Materials required include MSPs, phospholipids and polystyrene bio beads [51-54].

\section{Membrane scaffold protein}

The membrane scaffold protein is the improved Apo A1 which is made using recombinant technology from human blood, is expressed in bacteria. Different MSP clones coding for different sized proteins is produced by the Sligar lab [55]. MSP is produced in a soluble form in Escherichia. coli and by using $\mathrm{Ni}^{2+}$ affinity chromatography; it is purified $[48,29]$. The choice of MSP depends on the size of nanodisc required.

\section{Phospholipids}

1-palmitoyl-2-oleoyl-sn-glycero-3-phosphocholine, 1-palmitoyl-2oleoyl-sn-glycero-3-phospho-L-serine are some of the most commonly used phospholipids in nanodisc synthesis. Generally zwitterionic and negatively charged lipids are mixed to enhance mimicking the cell membrane. Bacterial membrane lipids have also been used for incorporation of bacterial proteins into nanodiscs [30].

\section{Polystyrene beads}

Beads must be washed with water and then using ethanol.

\section{Synthesis of nanodisc}

The first step involved in the synthesis of nanodisc is to collaborate together the MSP of appropriate class with the particular phospholipid or the detergent micelle. It is then followed by the elimination or removal of the detergent used [56]. As mentioned earlier, the size and stoichiometry of the nanodisc is being determined by the length of the scaffold protein that has been used. The MSP is actually a belt like structure that is wrapped around the protein. Next step is the determination of the phospholipid: MSP. This is a crucial step for the efficous assembling of nanodiscs. This has to be determined exactly for each new combination of MSP, the phospholipid and the protein. Then the protein solubilised in detergent is added to the disc mix. It has to be made ensured that this step is being done prior to the removal of the detergent. Thus the membrane protein has been merged into the nanodiscs. The major steps involving solublisation, detergent removal as well as assembling helps in the effective nanodisc synthesis and has been shown in fig. 2 .

\section{Reorganisation of proteins into nanodiscsc in three different ways}

\section{Cell free reaction system+arranged nanodiscs}

Detergents are not needed in this method of protein reconstitution. Membrane proteins can be made in cell free expression system. Preassembled nanodiscs are combined with the cell free reaction system and it ultimately results in joining or incorporation of the membrane protein into nano disk [57]. 


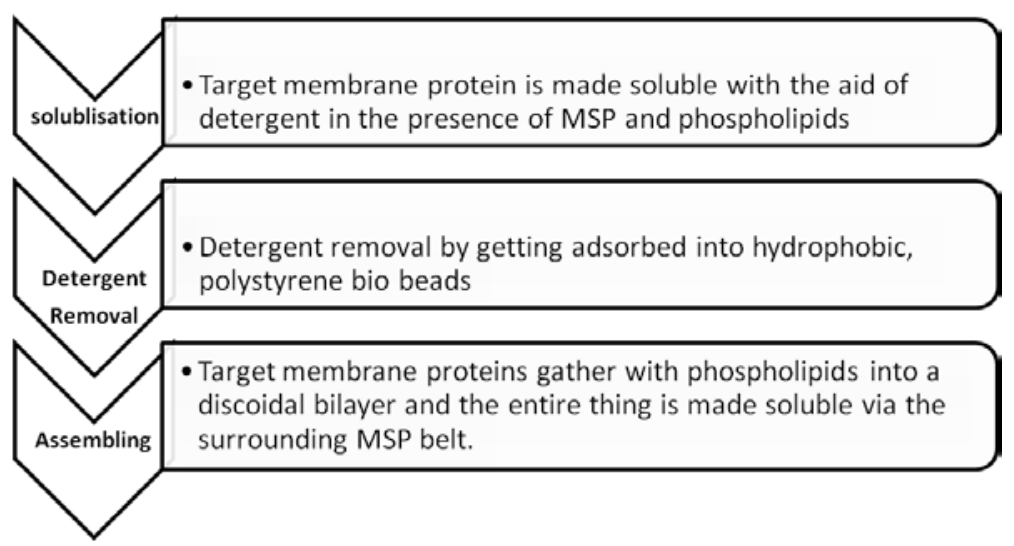

Fig. 2: Steps in nanodisc synthesis

\section{Previously solubilised membrane protein+detergent+MSP protein+phospholipid}

MSPs and phospholipids are added subsequently to the purified proteins. Nanodiscs incorporated with membrane proteins are formed and can be purified by chromatographic techniques.

\section{Detergent+MSP+protein expressed membrane}

To the protein expressed membrane, MSP $\mathrm{s}$ and detergents are added. Phospholipids, proteins etcetera in the membrane and MSP s align together to form the nano disc complex. This is beneficial in proteomic studies. Single nanodisc-protein complexes can also be isolated by various chromatographic techniques (affinity chromatography) $[58,53]$.

\section{Nanodisc reconstitution mixtures}

Nanodisc reconstitution mixtures can be prepared by using an efficient way involving chloroform, lipid stocks, nitrogen steam, and solvent removal by vaccum dessicator, lipid drying, addition of sodium cholate buffer and finally vortexing and sonicating as seen in fig. $3[53,22,59-61]$.

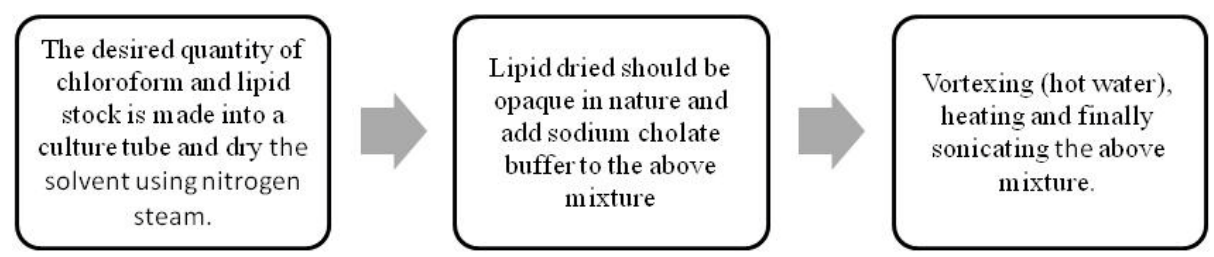

Fig. 3: Preparation of nanodisc reconstitution mixtures

\section{Applications of nanodiscs}

\section{The modern innovations in nanodiscs and cancer therapy}

The evolution of an eminent therapy for cancer has been one of the primarily focussed aspects not only in the medical field but also in terms of the society. Despite the availability of many cancer vaccines in the medicine field including peptide based vaccines for cancer therapy, their utility in humans was found to be limited only. The latest innovations in chemotherapy include personalised immune therapy which has been achieved with the aid of very specific neo antigens. The milestone behind this recent innovation was found to be due to the exome sequencing of tumour cells. The major limitation of this methodology was that the procedure of strongly activating the $\mathrm{CD} 8$ alpha+responses (in the Cyto toxic T lymphocyte Cells) was absent. The innovatory finding signalled first of all to the preparation of nanodiscs which has the property of mimicking the HDL [62]. Then the next step was to incorporate and pair the antigenic peptides along with the suitable adjuvants into the nanodiscs. The main purpose of this step is to enhance the recruitment of antigen and adjuvant to the lymphoid organs. It also results in sustaining the antigenic concentration within the cells [63]. Nanodiscs can be occasioned up to 47 doubling greater rates of neo antigen specific Cyto toxic T lymphocyte Cells (CTL s) than solvable vaccines. The subsequent nanodiscs can also be constructed with a rate more than 31 fold frequency of the adjuvant which is the stronger one. This procedure has been utilised in the trials that has been conducted clinically. It has been found that the growth of the tumour cells can be potentially eliminated by efficiently utilising this method [64]. The method consists of vaccines involving multi epitopes. The link between the evolution of multi epitope vaccines and the inhibition of tumour growth is the generation of broad spectrum responses of $\mathrm{T}$ Lymphocyte cells. The use of nanodiscs resulted in the elimination of MC 38 and B16 F10 tumours. This innovatory process resulted due to the pairing of subsequent nanodiscs with anti PD1 and anti CTLA 4 therapy for cancer [65, 7374]. Thus these revolutionary findings that correlate nanodiscs into the most useful accessory for cancer therapy paved the way of the evolution of this upcoming system into a powerful strategy for cancer personalised immunotherapy. The tumour cells get mutated to form neoantigens. The most basic idea behind a cancer vaccine involving nanodisc is as follows: The nanodisc is being encumbered with these mutated neoantigens [66]. This neoantigen loaded nanodisc signal the destruction of the cancer cells. Unlike the traditional preventive vaccine, this new vaccine concerning nanodisc is a therapeutic vaccine. The principle behind this vaccine is that it will bout against the cancer cells in a personalised method by the prompting of one's immune system [67].

Nanodisc technology represents a revolution in the capability of our understanding of the functionality of membrane proteins and provide advanced tenacity of strategic molecular events basic to a mechanistic understanding of the crucial metabolic as well as signalling functions and further there will be implication for the upcoming of much more effective intervention when those basic events get disrupted during some particular pathological conditions [68].

\section{Other applications}

Other major applications of nanodiscs include Nuclear magnetic Studies [69-70] surface plasma Resonance Studies [71-74], protein activation studies [53], binding studies of proteins etc. 


\section{CONCLUSION}

There has been constant experimenting on drug delivery studies ranging from nanoparticle drug delivery to microbial infectious sites to macromolecule studies of tissue regeneration. In the current scenario that finds drug targetting as one of the major challenges, nano drug delivery has a very important role especially in crossing the Blood Brain Barrier. The evolution of nanodiscs in membrane protein studies thus serve as a promising tool in novel drug delivery. The providence of a more native and genuine environment of nanodiscs when compared to others like liposomes, detergent micelles etc. once again proves the promising aspect of nanodisc. Nanodiscs can be synthesised in different size and also in different stoichiometry. It is dependent on the length of the MSP belt that is being used. Thus overall it can be stated as a promising novel aspect, in this era where a number of different tools including hydrotropes are under studies.

\section{ACKNOWLEDGEMENT}

We are immensely obliged and thankful to Dr. Sabitha M., principal, Amrita School of Pharmacy, Amrita Vishwa Vidyapeetham. We also extend our gratitude to the Department $f$ Pharmaceutics for catering legitimate facilities for carrying out the work.

\section{AUTHORS CONTRIBUTIONS}

All the authors have contributed equally.

\section{CONFLICT OF INTERESTS}

Declared none.

\section{REFERENCES}

1. Brigger I, Dubernet C, Couvreur P. Nanoparticles in cancer therapy and diagnosis. Adv Drug Delivery Rev 2002;54:631-51.

2. Yih TC, Al-Fandi M. Engineered nanoparticles as precise drug delivery systems. J Cell Biochem 2006;97:1184-90.

3. Unezaki S, Maruyama K, Hosoda JI, Koyanagi Y, Nakata M, Ishida 0 et al. Direct measurement of the extravasation of polyethyleneglycol-coated liposomes into solid tumor tissue by in vivo fluorescence microscopy. Int J Pharm 1996;144:11-7, 24.

4. Hobbs K, Monsky WL, Yuan F, Roberts WG, Griffith L, Torchilin VP, et al. Regulation of transport pathways in tumor vessels: role of tumor type and microenvironment. Proc Natl Acad Sci USA 1998;95:4607-12.

5. Basavaraj KH. Nanotechnology in medicine and relevance to dermatology: present concepts. Indian J Dermatol 2012;57: 169-74.

6. Allen TM, Cullis PR. Drug delivery systems entering the mainstream. Science 2004;303:1818-22.

7. Hughes G. Nanostructure-mediated drug delivery. Nanomedicine 2005;1:22-30.

8. Fars KA, Awwad AR, Ibrahim AA. Biopharmaceutical applications of nanogold. Saudi Pharm J 2010;18:179-93.

9. Wilczewska AZ, Niemirowicz $\mathrm{K}$, Markjewicz $\mathrm{KH}, \mathrm{Car} \mathrm{H}$. Nanoparticles as drug delivery systems. Pharmacol Rep 2012; 64:1020-37.

10. Reza K, Mohsen J. Revolutionary impact of nanodrug delivery on neuroscience. Curr Neuropharmacol 2012;1:370-92.

11. Singh R, Lilard JW. Nanoparticle-based targeted drug delivery. Exp Mol Pathol 2009;86:215-23.

12. Sarabjeet SS, Hicham F, Baljit S. Nanotechnlogy based drug delivery systems. J Occup Med Toxicol 2007;16:2-16.

13. Cerna T, Stiborova M, Adam V, Kizek R, Eckschlager TN. Nanocarrier drugs in the treatment of brain tumors. J Cancer Metastasis Treat 2016;2:407-16.

14. Koichiro T. Herbal pleiotropy-the scientific investigation may advance medicine. Int J Pharm Pharm Sci 2014;6:1-4.

15. Tewodros M, Ashley M, Nagesh K, Carolina S, Jinjun S, Daniel RK, et al. Emerging nanotechnology approaches for HIV/AIDS treatment and prevention. Nanomedicine 2010;5:269-85.

16. Sandeep S, Vivek KP, Ravi PT, Vishnu A. Nanoparticle based drug delivery system: advantages and applications. Indian J Sci Technol 2011;4:177-80.
17. Aswathy SN, Vidya KM, Saranya TR, Sreeja CN. Emulsomes: a novel liposomal formulation for sustained drug delivery. Int Res J Pharm App Sci 2013;3:192-6.

18. Thamburu S, Shammika P, Sabitha M, Sreeja CN. Chitosaneudragit magnetic microspheresof sulfasalazine for colon drug delivery. Int J Pharm Sci Rev Res 2016;41:125-31.

19. Shah H, Patel J. Bicelle: a lipid nanostructurefor transdermal delivery. J Crit Rev 2016;3:17-22.

20. Bayburt TH, Carlson JW, Sligar SG. Reconstitution and imaging of a membrane protein in a nanometer-size phospholipid bilayer. J Struct Biol 1998;123:7-44.

21. Hiroaki K, Keisuke I, Minoru N. Formation of size controlled, denaturation resistant lipid nanodiscs by an amphiphilic selfpolymerizing peptide. Colloids Surfaces B 2016;146:423-30.

22. Civjan NR, Bayburt TH, Schuler MA, Sligar SG. Direct solubilization of heterologously expressed membrane proteins by incorporation into nanoscale lipid bilayers. Bio Techniques 2003;35:556-63.

23. Jonas A. Reconstitution of high-density lipoproteins. Methods Enzymol 1986;128:553-82..

24. Pandit A, Schirzad Wasei N, Wlodarczyk LM, Van Roon H, Boekema EJ, Dekker JP, et al. Assembly of major light-harvesting complex II in lipid nanodiscs. Biophys J 2011;101:2507-15.

25. Schuler MA, Denisov IG, Sligar SG. Nanodiscs as a new tool to examine lipid-protein interactions. Methods Mol Biol 2013;74:415-33.

26. Ashkan D, Valeria C, Ian WH. Self assembling amphiphilic peptides. J Pept Sci 2014;20:453-67.

27. William BL, David RK, Brandon VS, Nicholas AP. Polymers for drug delivery systems. Annu Rev Chem Biomol Eng 2010;1:149-73.

28. El Moustaine D, Granier S, Doumazane E, Scholler P, Rahmeh R, Bron P. Distinct roles of metabotropic glutamate receptor dimerization in agonist activation and G-proteincoupling. Proc Natl Acad Sci USA 2012;109:16342-7.

29. Mitra N, Liu Y, Liu J, Serebryani E, Mooney V, DeVree BT, et al. Calcium-dependent ligand binding and G-protein signaling of family B GPCR parathyroid hormone 1 receptor purified in nanodiscs. ACS Chem Biol 2013;8:617-25.

30. Bhama SK, Rakhi K, Lakshmi P, Deepa TV, Sreeja CN. Formulation and evaluation of niosomal suspension of cefixime. Asian J Pharm Clin Res 2017;10:194-201.

31. Borch J, Torta F, Sligar SG, Roepstorff P. Nanodiscs for immobilization of lipid bilayers and membrane receptors: kinetic analysis of cholera toxin binding to a glycolipid receptor. Anal Chem 2008;80:6245-52.

32. Jonas A. Reconstitution of high-density lipoproteins. Methods Enzymol 1986;128:553-82.

33. Silva RA, Huang R, Morris J, Gracheva EO, Ren G, Kontush A, et al. Structure of apolipoprotein A-I in spherical high density lipoproteins of different sizes. Proc Natl Acad Sci USA 2008;105:12176-81.

34. Gnaneswaran S, Kuberan D, Vinodhini VM, Swamy RSV, Ebenezer WW, Kumar JS. Fasting plasma glucose and glycolated haemoglobin in prediction of diabetic retinopathy in rural population. Int J Pharm Clin Res 2014;6:40-5.

35. Soumya S, Doney AB, Sabitha M. Current trends in lipid based delivery systems and its applications in drug delivery. Asian J Pharm Clin Res 2012;4:4-9.

36. Wijtske A, Uwe JFT. Regulation of reverse cholesterol transport-a comprehensive appraisal of available animal studies. Nutr Metab 2012;9:70759-25.

37. Astrid EV. Reverse cholesterol transport: from classical view to new insights. World J Gastroenterol 2010;16:5908-15.

38. Tall AR. An overview of reverse cholesterol transport. Eur Heart J 1998;19 Suppl A:A31-5.

39. Amy YS, Sligar SG, Schluten K. Maturation of high-density lipoproteins. J R Soc Interface 2009;6:863-71.

40. Vijey A, Samuel GG. Structure affinity relationship and characterization of benzoporphyrins as potent inhibitors of YAP oncoprotein in silico experiments. Int J Pharm Pharm Sci 2015; 7:278-84.

41. Denisov IG, Sligar SG. Nanodiscs for structural and functional study of membrane proteins. Nat Struct Mol Biol 2016;23:481-6. 
42. Borch J, Hamann T. The nanodisc: a novel tool for membrane protein studies. Biol Chem 2009;390:805-14.

43. Hagn F, Etzkorn M, Raschle T, Wagner G. Optimized phospholipid bilayer nanodiscs facilitate high resolution structure determination of membrane proteins. J Am Chem Soc 2013;135:1919-25.

44. Rouck JE, Krapf JE, Roy G, Huff HC, Das A. Recent advances in nanodisc technology for membrane protein studies. FEBS Lett 2017;591:2057-88.

45. Bayburt TH, Sligar SG. Membrane protein assembly into nanodiscs. FEBS Lett 2010;58:1721-7.

46. Shefrin S, Sreelaxmi CS, Vishnu V, Sreeja CN. Enzymosomes: a rising effectual tool for targeted drug delivery system. Int J Appl Pharm 2017;9:1-9.

47. Denisov IG, Sligar SG. Cytochromes $\mathrm{P}_{450}$ in nanodiscs. Biochim Biophys Acta 2011;1814:223-9.

48. Ritchie TK, Grinkova YV, Bayburt TH, Denisov IG, Zolnerciks JK, Atkins WM, et al. Reconstitution of membrane proteins in phospholipid bilayer nanodiscs. Methods Enzymol 2009; 464:211-31.

49. Bayburt TH, Sligar SG. Membrane protein assembly into nanodiscs. FEBS Lett 2010;584:1721-7.

50. Nath A, Atkins WM, Sligar SG. Applications of phospholipid bilayer nanodiscs in the study of membranes and membrane proteins. Biochemistry 2007;46:2059-69.

51. Denisov IG, McLean MA, Shaw AW, Grinkova YV, Sligar SG Thermotropic phase transition in soluble nanoscale lipid bilayers. J Phys Chem B 2005;109:15580-8.

52. Banerjee S, Huber T, Sakmar T. Rapid incorporation of functional rhodopsin into nanoscale apo lipoprotein bound bilayer particles. J Mol Biol 2008;377:1067-81.

53. Thenesh SK, Oshin S, Sudharsan CR. Efficacy of Hydrotropes on the Solubility of Forskolin in Water. Int J Appl Pharm 2016;8:1-4.

54. Kunjan P, Marika N, Rupanjali BS, Hemanta KS. Nanosized Drug Delivery Systems for Direct Nose to Brain Targeting: A Review. Recent Pat Drug Delivery Formul 2016;10:156-64.

55. Denisov IG, Grinkova YV, Lazarides AA, Sligar SG. Directed selfassembly of monodisperse phospholipid bilayer nanodiscs with controlled size. J Am Chem Soc 2004;126:3477-87.

56. Bayburt TH, Grinkova YV, Sligar SG. Self-assembly of discoidal phospholipid bilayer nanoparticles with membrane scaffold proteins. Nanoletters 2002;2:853-6.

57. Dhanalakshmi V, Nimal TR, Sabitha M, Biswas R, Jayakumar R. Skin and muscle permeating antibacterial nanoparticles for treating Staphylococcus aureus infected wounds. J Biomed Mater Res Part B Appl Biomater 2016;1:797-807.

58. Serebryany, Zhu GA, Yan YC. Artificial membrane-like environments for in vitro studies of purified G-protein coupled receptors. Biochem Biophys Acta 2012;1818:225-33.
59. Sligar SG. Finding a single-molecule solution for membrane proteins. Biochem Biophys Res Comm 2003;312:115-9.

60. Jayakumar R. Biological macromolecules for tissue regeneration. Int J Biol Macromol 2016;93:1337.

61. Glueck JM, Koenig BW, Wilbold D. Nanodiscs allow the use of integral membrane proteins as analytes in surface plasmon resonance studies. Anal Biochem 2011;408:46-52.

62. Kuai R. Designer vaccine nanodisc for personalised cancer immunotherapy. Nat Mater 2016;16:489-96.

63. Karasaki T, Nakajima J, Kakimi K. Neoantigens and wholeexome sequencing. Gan Kaqaku Ryoho 2016;43:791-7.

64. Hirayama M, Nishimur Y. The present status and future prospects of peptide-based cancer vaccines. Int Immunol 2016;28:319-28.

65. Desrichard A, Synder A, Chan TA. Cancer neoantigens and applications for immunotherapy. Clin Cancer Res 2016;22:807-12.

66. Glueck JM, Wittlich M, Feuerstein S, Hoffmann S, Willbold D, Koeniq BW. Integral membrane proteins in nanodiscs can be studied by solution NMR spectroscopy. J Am Chem Soc 2009;131:12060-1.

67. $\mathrm{Xu} \mathrm{Z,} \mathrm{Wang} \mathrm{Y,} \mathrm{Zhang} \mathrm{L,} \mathrm{Huang} \mathrm{L.} \mathrm{Nanoparticle-delivered}$ transforming growth factor-beta siRNA enhances vaccination against advanced melanoma by modifying tumor microenvironment. ACS Nano 2014;8:3636-45.

68. Zhanq X, Sharma PK, Peter Goedegebuure S, Gillanders WE. Personalised cancer vaccines targeting the cancer mutanom Vaccine 2017;35:1094-100.

69. Hagn F, Etzkorn M, Raschle T, Wagner G. Optimized phospholipid bilayer nanodiscs facilitate high-resolution structure determination of membrane proteins. J Am Chem Soc 2013;135:1919-25.

70. Iacono P, Battaglia PM, Falcomata B, Bandello F. Central serous chorioretinopathy treatments: a mini review. Ophthalmic Res 2016;55:76-83.

71. Aswathy SN, Vidya KM, Saranya TR, Sreeja CN. Emulsomes: a novel liposomal formulation for sustained drug delivery. Int Res J Pharm Appl Sci 2013;3:192-6.

72. Shen HM, Zhang QF. Risk assessment of nickel carcinogenicity and occupational lung cancer. Environ Health Perspect 1994;102 Suppl 1:275-82.

73. Payne DK, Sullivan MD, Massie MJ. Women's psychological reactions to breast cancer. Semin Oncol 1996;23(1, Suppl 2):89-97.

74. Januz B, Joanna P, Joanna Z. Nanoparticles of titanium and zinc oxides as novel agent in tumor treatment: a review. Nanoscale Res Lett 2017;12:1-15.

75. Atyabi F, Sharma HL, Mohammad HAH, Fell JT. Controlled drug release from coated floating ion exchange resin beads. J Controlled Release 1996;42:25-8. 